\title{
Natural Convection Heat Transfer In Trapezoidal Enclosure with Baffles Attached to Heated Wall
}

\author{
Ziad M. Al-Makhyoul \\ Lecturer \\ Department of Mechanical Engineering-University of Mosul-Iraq
}

\begin{abstract}
A two-dimensional solution of natural convection heat transfer in a trapezoidal enclosure using baffles attached to hot wall has been analyzed numerically. The vertical and inclined walls of the enclosure are isothermal while the bottom and top horizontal walls are insulated and the temperature of the vertical wall is higher than the temperature of the inclined wall. Governing equations are solved using the finite difference technique. The study included three cases: one baffle at position 0.5 , two baffles at positions 0.2 and 0.5 , and three baffles at positions $0.2,0.4$ and 0.6 , in addition to Rayleigh number $10^{3}, 10^{4}$ and $10^{5}$ and baffle length of $0.2,0.3$ and 0.4 used as governing parameters that are effective on heat transfer and fluid flow. Results for the mean Nusselt number, and contour maps of the streamlines and isotherms are presented. It is found that Nusselt number is an increasing with increasing in Rayleigh number while decreasing with increasing in the baffle length and number of baffles.
\end{abstract}

Key words: Natural convection, Trapezoidal enclosure, Heat transfer, baffles

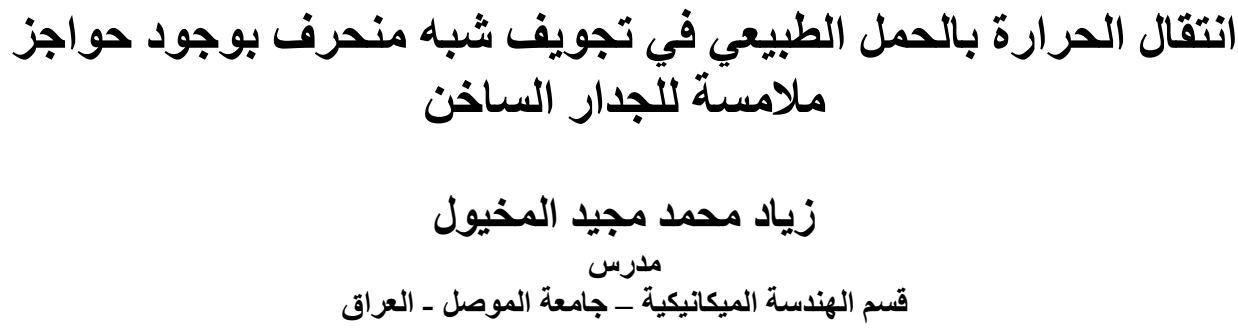

الخلاصة

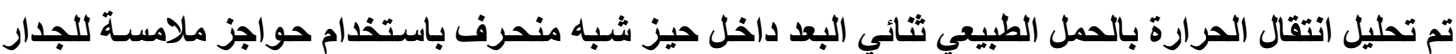

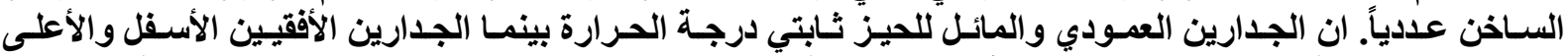

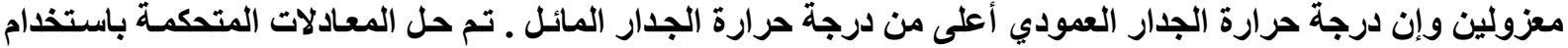

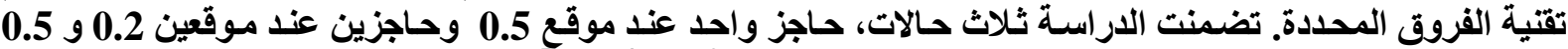

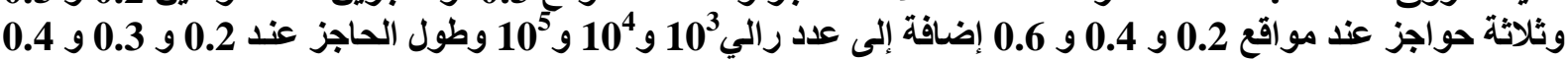

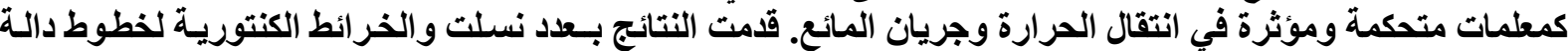

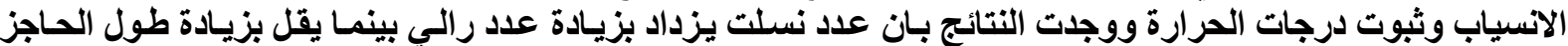

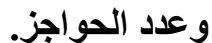
الكلمات المفتاحية: الحمل الطبيعي ، حيز شبه منحرف ، انتقال الحرارة ، حواجز 


\section{Nomenclature}

\begin{tabular}{|l|l|l|l|}
\hline $\mathrm{L}$ & Bottom horizontal and vertical lengths & $\mathrm{y}_{\mathrm{f}}$ & Baffle length from horizontal surface $(\mathrm{m})$ \\
\hline $\mathrm{L}_{1}$ & Top horizontal length $(\mathrm{m})$ & $\mathrm{Y}_{\mathrm{f}}$ & $\begin{array}{l}\text { Dimensionless baffle length from horizontal } \\
\text { surface }\end{array}$ \\
\hline $\mathrm{l}_{\mathrm{f}}$ & Baffle length $(\mathrm{m})$ & $\psi$ & Stream function $\left(\mathrm{m}^{2} / \mathrm{s}\right)$ \\
\hline $\mathrm{L}_{\mathrm{f}}$ & Dimensionless baffle length & $\hat{\psi}$ & Dimensionless stream function \\
\hline $\mathrm{Nu}$ & Nusselt number & $\omega$ & Vorticity \\
\hline $\mathrm{P}$ & Fluid pressure $(\mathrm{Pa})$ & $\Omega$ & Dimensionless velocity \\
\hline $\mathrm{Pr}$ & Prandtl numbers $(\mathrm{v} / \alpha)$ & $\theta$ & Dimensionless temperature $=\left(\mathrm{T}_{-} \mathrm{T}_{\mathrm{c}}\right) /\left(\mathrm{T}_{\mathrm{h}}-\mathrm{T}_{\mathrm{c}}\right)$ \\
\hline $\mathrm{Q}_{\text {cond. }}$ & Conduction heat transfer $(\mathrm{W})$ & $\rho$ & Density $\left(\mathrm{kg} / \mathrm{m}^{3}\right)$ \\
\hline $\mathrm{Q}_{\text {conv. }}$ & Convection heat transfer $(\mathrm{W})$ & $v$ & Kinematic viscosity $\left(\mathrm{m}^{2} / \mathrm{s}\right)$ \\
\hline $\mathrm{Ra}$ & Rayleigh number $\left[\mathrm{g} \beta \mathrm{L}^{3}\left(\mathrm{~T}_{\mathrm{h}}-\mathrm{T}_{\mathrm{c}}\right) / \mathrm{v} \alpha\right]$ & $\phi$ & Arbitrary function \\
\hline $\mathrm{T}$ & Temperature $\left({ }^{\circ} \mathrm{K}\right)$ & $\alpha$ & Thermal diffusivity $\left(\mathrm{m}^{2} / \mathrm{s}\right)$ \\
\hline $\mathrm{u}$ & Velocity in x direction $(\mathrm{m} / \mathrm{s})$ & $\beta$ & Thermal expansion coefficient $\left(1 /{ }^{\circ} \mathrm{K}\right)$ \\
\hline $\mathrm{v}$ & Velocity in y direction $(\mathrm{m} / \mathrm{s})$ & $\mu$ & Viscosity $\left(\mathrm{N} . \mathrm{s} / \mathrm{m}^{2}\right)$ \\
\hline $\mathrm{x}$ & Horizontal distance $(\mathrm{m})$ & Subscripts \\
\hline $\mathrm{X}$ & Dimensionless horizontal distance & \multicolumn{2}{|l|}{} \\
\hline $\mathrm{y}$ & Vertical distance $(\mathrm{m})$ & $\mathrm{h}$ & Hot \\
\hline $\mathrm{Y}$ & Dimensionless vertical distance & $\mathrm{c}$ & Cold \\
\hline
\end{tabular}

\section{Introduction:}

Natural convection heat transfer in enclosures has been a topic for many studies found in the literature. In these studies, square, rectangular, inclined, slender and shallow cavities with various wall conditions have been considered extensively by different researchers. However, cavities with baffles attached to the wall(s) have received less consideration. There are many industrial applications where the heat transfer through a fluid layer contained in an enclosure is desired to be controlled. Such applications are seen in solar collectors, nuclear reactors, heat exchangers and electronic equipments. The rate of heat transfer through a fluid layer in an enclosure may be controlled by attaching baffles to one of the active walls of the enclosure. Properly placing baffles on the active wall(s) of an enclosure, the heat transfer rate may be reduced or enhanced. Hence, studying heat transfer through a fluid layer enclosed in a cavity with baffles attached to its wall(s) has value from practical as well as theoretical point of views. Baffles are also used in flow channels to control the heat transfer rate across the channel walls [1].

Karyakin [2] reported two dimensional laminar natural convection in isosceles trapezoidal cavity. The heat transfer rate is found to increase with the increase in base angle. Peric [3] studied natural convection in a trapezoidal cavities using control volume method and observed the convergence of results for grid independent solutions.

Kuyper and Hoogendoorn [4] investigated laminar natural convection flow in trapezoidal enclosures also the dependence of the average Nusselt number on the Rayleigh number. Sadat and Salagnac [5] carried out numerical investigations on solution of laminar natural convection using vorticity-stream function formulation. Steady state solutions were obtained for aspect ratios ( 3 and 6) and finally, they presented flow patterns and average heat transfer characteristics.

Eyden et al. [6] presented numerical and experimental results for turbulent double diffusive convection of a mixture of two gases in a trapezoidal enclosure with imposed unstable thermal stratification. The numerical results on mean velocity, temperature and 
concentration, show satisfactory agreement with measurements, indicating that despite some deficiencies, the numerical model can reproduce most of the essential features of the process.

Papanicolaou and Belessiotis [7] studied numerically double-diffusive natural convection in asymmetric trapezoidal enclosure. Their numerical investigation is based on a two-equation, low-Reynolds number turbulence model involving a curvilinear coordinate system. Their numerical solutions yield a multi-cellular flow field, with the number of cells depending on the Rayleigh number for a fixed Lewis number and geometry.

Natarajan et al. [8] investigated the influence of uniform and non-uniform heating of bottom wall on natural convection flows in a trapezoidal cavity. In the present investigation, bottom wall is uniformly and non-uniformly heated while two vertical walls are maintained at constant cold temperature and the top wall is well insulated. Parametric study for the wide range of Rayleigh number from $\left(10^{3}\right.$ to $\left.10^{5}\right)$ and Prandtl number from (0.07 to 100) shows consistent performance of the present numerical approach to obtain the solutions in terms of stream functions and the temperature profiles. Non-uniform heating of the bottom wall produces greater heat transfer rate at the center of the bottom wall than uniform heating case for all Rayleigh numbers but average Nusselt number shows overall lower heat transfer rate for non-uniform heating case.

Kasayapanand [9] presented numerical modeling of the electric field effect on natural convection in square enclosures with single baffle and multiple baffles are investigated. The interactions between electric, flow and temperature fields are analyzed using a computational fluid dynamic technique. The parameters considered are the supplied voltage, Rayleigh number, size of enclosure, electrode arrangement, number of baffle and baffle length. It can be concluded that the flow and heat transfer enhancements are the decreasing function of Rayleigh number.

Tanmay et al. [10] studied the natural convection in trapezoidal enclosures for uniformly heated bottom wall, linearly heated vertical wall(s) in presence of insulated top wall have been investigated numerically with penalty finite element method. Parametric studies for the wide range of Rayleigh numbers $\left(10^{3}\right.$ to $\left.10^{5}\right)$ and Prandtl number from $(0.7$ to 1000) with various tilt angles of side walls. The secondary circulations are stronger near the top portion of the left wall especially for larger Prandtl number. Streamlines show that the strength of convection is larger for the angle of inclination wall of $\left(45^{\circ}\right)$ and flow intensities are found to be larger for higher Prandtl numbers. Average Nusselt number plots show higher heat transfer rates for the angle of inclination wall of $\left(0^{\circ}\right)$.

Tanmay et al. [11] presented numerical study deals with natural convection flow in closed trapezoidal enclosures. The detailed analysis is carried out in two case (1) linearly heated side walls; (2) linearly heated left wall and cold right wall. In both the cases bottom wall is uniformly heated and top wall is well insulated. In case (1), It is found that, less intense circulations occurs in square cavity the angle of inclination of $\left(90^{\circ}\right)$ compared to other cavities an angles of $\left(45^{\circ}\right.$ and $\left.60^{\circ}\right)$. In case (2), the cold right wall receives larger amount of heat from bottom wall compared to that of linearly heated left wall. The local and average Nusselt numbers are also illustrated using heat lines. It is found that, $\mathrm{Nu}$ distribution exhibits sinusoidal variation at Prandtl number is (1000) in case 1.

Moukalled and Darwish [12] studied numerically the effects on heat transfer of mounting baffles to the upper inclined surfaces of trapezoidal cavities using two thermal boundary conditions, the first, the left short vertical wall is heated while the right long vertical wall is cooled. In the second, the right long vertical wall is heated while the left short vertical wall is cooled. For both boundary conditions, predictions reveal a decrease in heat transfer in 
the presence of baffles with its rate generally increasing with increasing baffle height and Prandtl number. For a given baffle height, higher decrease in heat transfer is generally obtained with baffles located close to the short vertical wall. Average Nusselt number correlations for both boundary conditions are presented.

The purpose of the present work is to studying the natural convection heat transfer inside a trapezoidal enclosure with a three cases, one, two and three baffles attached to hot wall while the inclined wall is cold. The effects of the baffle length, Rayleigh number and number of baffles on the flow field and the heat transfer rate are studied.

\section{Definition of physical model}

The schematic configuration of the physical model and finite difference grid are plotted in figure (1-a-b) that shows a two dimensional trapezoidal enclosure subjected to the boundary conditions as isothermal vertical wall, the left is hot $\left(\mathrm{T}_{\mathrm{h}}\right)$ and the right wall is inclined at cold temperature $\left(\mathrm{T}_{\mathrm{c}}\right)$ while the horizontal walls are insulated. The horizontal baffles are attached to the vertical heated wall at length $\mathrm{L}_{\mathrm{f}}$ and positions $\mathrm{Y}_{\mathrm{f} 1}, \mathrm{Y}_{\mathrm{f} 2}$ and $\mathrm{Y}_{\mathrm{f} 3}$ as a dimensionless respect to $\mathrm{L}$.

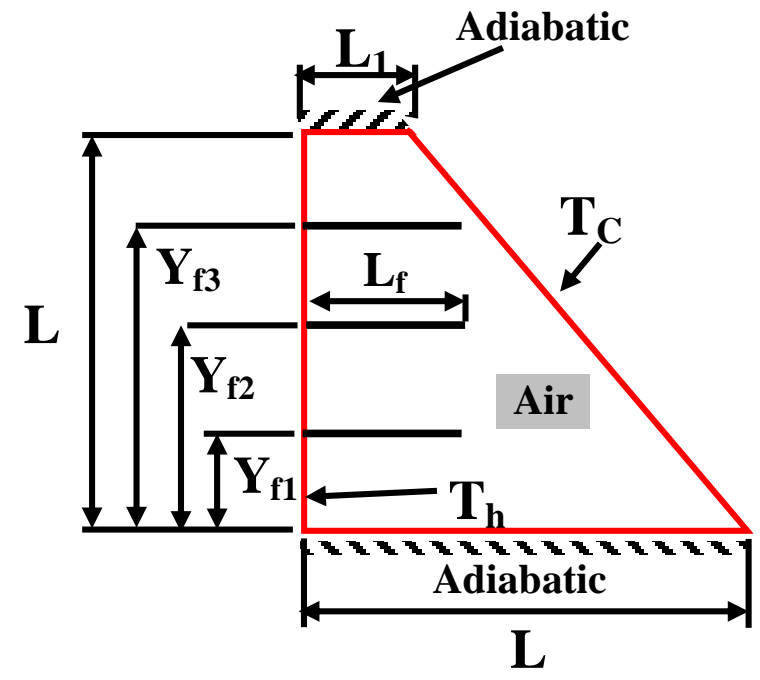

(a)

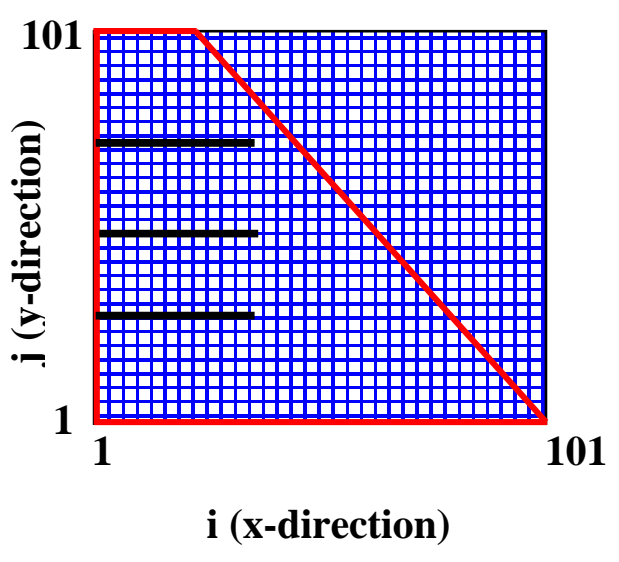

(b)

Figure (1): a- Geometry of trapezoidal enclosure with baffles

b- Finite difference grid for a trapezoidal enclosure with baffles

To simplify the analysis, the following assumptions are made:

1- The fluid is incompressible, steady and laminar.

2- A two-dimensional distribution of fluid flow and temperature

3- The fluid have a constant properties.

4- The fluid is Newtonian and the Boussinesq approximation.

5- The radiation effect can be taken to be negligible.

Equations which govern the heat transfer and fluid flow are:

1-The continuity equation for the steady form and incompressible flow is given by:

$\frac{\partial \mathrm{u}}{\partial \mathrm{x}}+\frac{\partial \mathrm{v}}{\partial \mathrm{y}}=0$

2-The energy equation which depending on the considered assumption, the steady flow and constant property of fluid with no heat generation energy equation is: 
$\mathrm{u} \frac{\partial \mathrm{T}}{\partial \mathrm{x}}+\mathrm{v} \frac{\partial \mathrm{T}}{\partial \mathrm{y}}=\alpha\left[\frac{\partial^{2} \mathrm{~T}}{\partial \mathrm{x}^{2}}+\frac{\partial^{2} \mathrm{~T}}{\partial \mathrm{y}^{2}}\right]$

3-The momentum equation $\mathrm{x}$-direction can be written as:

$u \frac{\partial u}{\partial x}+v \frac{\partial u}{\partial y}=-\frac{1}{\rho} \frac{\partial p}{\partial x}+\mu\left[\frac{\partial^{2} u}{\partial x^{2}}+\frac{\partial^{2} u}{\partial y^{2}}\right]$

And in $\mathrm{y}$-direction is:

$\mathrm{u} \frac{\partial v}{\partial \mathrm{x}}+v \frac{\partial v}{\partial \mathrm{y}}=-\frac{1}{\rho} \frac{\partial \mathrm{p}}{\partial \mathrm{y}}+\mu\left[\frac{\partial^{2} \mathrm{u}}{\partial \mathrm{x}^{2}}+\frac{\partial^{2} \mathrm{u}}{\partial \mathrm{y}^{2}}\right]-\rho^{*} \mathrm{~g}$

Using the Boussinesq approximation in the density is constant in all terms in the governing equation and can be written as:

$\rho=\rho_{\mathrm{o}}(1-\beta \Delta \mathrm{T})$

After substitution equation (5) in (4), the equation will yields:

$\mathrm{u} \frac{\partial v}{\partial \mathrm{x}}+v \frac{\partial v}{\partial \mathrm{y}}=-\frac{1}{\rho} \frac{\partial \mathrm{p}}{\partial \mathrm{y}}+\mu\left[\frac{\partial^{2} \mathrm{v}}{\partial \mathrm{x}^{2}}+\frac{\partial^{2} \mathrm{v}}{\partial \mathrm{y}^{2}}\right]+\mathrm{g} \beta \Delta \mathrm{T}$

The stream functions and vorticity can be written as:

$\mathrm{u}=\frac{\partial \psi}{\partial \mathrm{y}}, \quad \mathrm{v}=-\frac{\partial \psi}{\partial \mathrm{x}}, \quad \omega=\left(\frac{\partial \mathrm{v}}{\partial \mathrm{x}}-\frac{\partial \mathrm{u}}{\partial \mathrm{y}}\right)$

The stream function formulation satisfies continuity equation and by substituting them in the continuity equation yield:

$\frac{\partial^{2} \psi}{\partial \mathrm{x}^{2}}+\frac{\partial^{2} \psi}{\partial \mathrm{y}^{2}}=-\omega$

After substituting the energy equation can be given as:

$\frac{\partial \psi}{\partial \mathrm{y}} \frac{\partial \mathrm{T}}{\partial \mathrm{x}}-\frac{\partial \psi}{\partial \mathrm{x}} \frac{\partial \mathrm{T}}{\partial \mathrm{y}}=\frac{\partial}{\partial \mathrm{x}}\left(\frac{\mu}{\operatorname{Pr}} \frac{\partial \mathrm{T}}{\partial \mathrm{x}}\right)+\frac{\partial}{\partial \mathrm{y}}\left(\frac{\mu}{\operatorname{Pr}} \frac{\partial \mathrm{T}}{\partial \mathrm{y}}\right)$

Dimensionless governing equations in streamline-vorticity form can be obtained via introducing dimensionless variable as follows:

$\mathrm{X}=\frac{\mathrm{x}}{\mathrm{L}}, \quad \mathrm{Y}=\frac{\mathrm{y}}{\mathrm{L}}, \quad \hat{\psi}=\frac{\psi \operatorname{Pr}}{\mathrm{v}}, \quad \Omega=\frac{\omega(\mathrm{L})^{2} \operatorname{Pr}}{\mathrm{v}}, \quad \mathrm{Y}_{\mathrm{f}}=\frac{\mathrm{y}_{\mathrm{f}}}{\mathrm{L}}, \quad \mathrm{L}_{\mathrm{f}}=\frac{1_{\mathrm{f}}}{\mathrm{L}}$

$\theta=\frac{\mathrm{T}-\mathrm{T}_{\mathrm{c}}}{\mathrm{T}_{\mathrm{h}}-\mathrm{T}_{\mathrm{c}}}, \quad \mathrm{U}, \mathrm{V}=\frac{(\mathrm{u}, \mathrm{v}) \mathrm{L}}{\alpha}$

Using non dimensional variables which defined above the governing equations are obtained as:

1- Continuity equation:

$\frac{\partial \hat{\psi}}{\partial \mathrm{X}^{2}}+\frac{\partial \hat{\psi}}{\partial \mathrm{Y}^{2}}=-\Omega$

2- Energy equation:

$\frac{\partial \hat{\psi}}{\partial \mathrm{Y}} \frac{\partial \theta}{\partial \mathrm{X}}-\frac{\partial \hat{\psi}}{\partial \mathrm{X}} \frac{\partial \theta}{\partial \mathrm{Y}}=\frac{1}{\operatorname{Pr}}\left(\frac{\partial^{2} \theta}{\partial \mathrm{X}^{2}}+\frac{\partial^{2} \theta}{\partial \mathrm{Y}^{2}}\right)$

3- Momentum equation:

$\frac{\partial \hat{\psi}}{\partial Y} \frac{\partial \Omega}{\partial X}-\frac{\partial \hat{\psi}}{\partial X} \frac{\partial \Omega}{\partial Y}=\frac{R a}{\operatorname{Pr}} * \frac{\partial \theta}{\partial x}+\frac{\partial^{2} \Omega}{\partial X^{2}}+\frac{\partial^{2} \Omega}{\partial Y^{2}}[12]$ 
The boundary conditions are illustrated in the physical model and they can be defined as followings:

At:

$\mathrm{X}=1 \quad$ and $\quad 0 \leq \mathrm{Y} \leq 1 \quad \theta=0$

$\mathrm{X}=0$ and $\quad 0 \leq \mathrm{Y} \leq 1 \quad \theta=1$

$0 \leq \mathrm{X} \leq \mathrm{L}$ and $\mathrm{Y}=0 \frac{\partial \theta}{\partial \mathrm{y}}=0$

$0 \leq \mathrm{X} \leq \mathrm{L}$ and $\mathrm{Y}=1 \frac{\partial \theta}{\partial \mathrm{y}}=0$

For baffle:

$0 \leq \mathrm{X} \leq \mathrm{L}_{\mathrm{f}}$ and $\mathrm{Y}=\mathrm{Y}_{\mathrm{f}} \quad \frac{\partial \theta}{\partial \mathrm{n}}=0$

\section{Numerical solution}

The governing equation for steady state, laminar and two dimensional natural convection heat transfer in a trapezoidal enclosure with thin baffles attached to the hot wall are solved using the finite difference technique (Taylor series) which is effective and simple in formulation with numerical accuracy in results.

For any unknown variable points $\phi(\mathrm{x}, \mathrm{y})$, the continuous first and second order derivatives at grid point $(\mathrm{I}, \mathrm{j})$, which are $(\partial \phi / \partial \mathrm{x})_{\mathrm{i}, \mathrm{j}}$ and $\left(\partial^{2} \phi / \partial \mathrm{x}^{2}\right)_{\mathrm{i}, \mathrm{j}}$ respectively may be expressed in three ways:

The forward difference approximation for the one side three points, the first and second derivatives are:

$$
\begin{aligned}
& \left(\frac{\partial \phi}{\partial x}\right)_{i, j}=\frac{-3 \phi_{i, j}+4 \phi_{i+1, j}-\phi_{i+2, j}}{2 \Delta x}+O(\Delta x)^{2} \\
& \left(\frac{\partial^{2} \phi}{\partial x^{2}}\right)_{i, j}=\frac{\phi_{i, j}-2 \phi_{i+1, j}+\phi_{i+2, j}}{(\Delta x)^{2}}+O(\Delta x)^{2}
\end{aligned}
$$

The backward difference approximation for the one side three point, the first and second derivatives are:

$$
\begin{aligned}
& \left(\frac{\partial \phi}{\partial x}\right)_{i, j}=\frac{-3 \phi_{i, j}+4 \phi_{i-1, j}-\phi_{i-2, j}}{2 \Delta x}+O(\Delta x)^{2} \\
& \left(\frac{\partial^{2} \phi}{\partial x^{2}}\right)_{i, j}=\frac{\phi_{i, j}-2 \phi_{i-1, j}+\phi_{i-2, j}}{(\Delta x)^{2}}+O(\Delta x)^{2}
\end{aligned}
$$

The central difference approximation for the internal nodes can be written as:

$$
\begin{aligned}
& \left(\frac{\partial \phi}{\partial \mathrm{x}}\right)_{\mathrm{i}, \mathrm{j}}=\frac{\phi_{\mathrm{i}+\mathbf{1}, \mathrm{j}}-\phi_{\mathrm{i}-\mathbf{1}, \mathrm{j}}}{2 \Delta \mathrm{x}}+\mathrm{O}(\Delta \mathrm{x})^{2} \\
& \left(\frac{\partial^{2} \phi}{\partial \mathrm{x}^{2}}\right)_{\mathrm{i}, \mathrm{j}}=\frac{\phi_{\mathrm{i}-\mathbf{1}, \mathrm{j}}-\mathbf{2} \phi_{\mathrm{i}, \mathrm{j}}+\phi_{\mathrm{i}+\mathbf{1}, \mathrm{j}}}{(\Delta \mathrm{x})^{2}}+\mathrm{O}(\Delta \mathrm{x})^{2}
\end{aligned}
$$


Where $\mathrm{O}(\Delta \mathrm{x})^{2}$ is the truncation error of second order.

The backward difference equations of irregular mesh nodes for the inclined wall can be showing in the figure (2) and written as:

$$
\begin{aligned}
& \left(\frac{\partial \phi}{\partial x}\right)_{i, j}=\frac{-3 \phi_{i, j}+4 \phi_{i-1, j}-\phi_{i-2, j}}{(1+a) \Delta x} \\
& \left(\frac{\partial \phi}{\partial x}\right)_{i, j}=\frac{-3 \phi_{i, j}+4 \phi_{i, j-1}-\phi_{i, j}-2}{(1+b) \Delta x} \\
& \left(\frac{\partial^{2} \phi}{\partial x^{2}}\right)_{i, j}=\frac{2}{\Delta x(1+a)}\left(\frac{\phi_{i+1, j}-\phi_{i, j}}{a \Delta x}-\frac{\phi_{i, j}-\phi_{i-1, j}}{\Delta x}\right) \\
& \left(\frac{\partial^{2} \phi}{\partial y^{2}}\right)_{i, j}=\frac{2}{\Delta y(1+b)}\left(\frac{\phi_{i, j+1}-\phi_{i, j}}{b \Delta y}-\frac{\phi_{i, j}-\phi_{i, j-1}}{\Delta y}\right)
\end{aligned}
$$
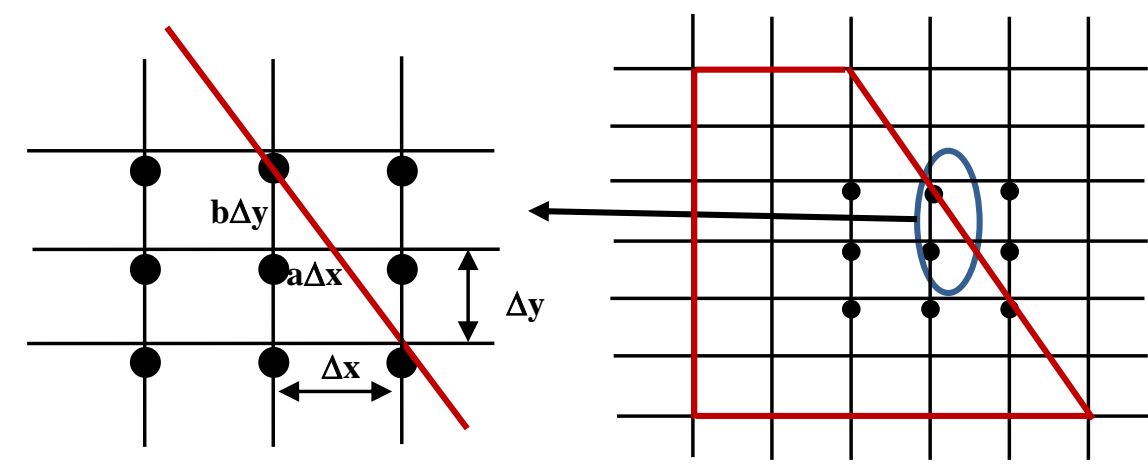

Figure (2): Finite difference grid for the inclined wall

The heat transfer from the walls of the enclosure can be obtained using the integration of temperature gradient along the vertical wall.

$\mathrm{Q}=\int_{0}^{\mathrm{A}}\left(\frac{\partial \theta}{\partial \mathrm{x}}\right)_{\mathrm{x}=0, \mathrm{~L}} \mathrm{dy}$

After computing the heat transfer in the enclosure, Nusselt number can be calculated as:

$$
\mathrm{Nu}=\frac{\mathrm{Q}_{\text {conv. }}}{\mathrm{Q}_{\text {cond. }}}
$$

\section{Results and discussion:}

The results for natural convection inside a trapezoidal enclosure with (one, two and three) thin baffles attached to the hot wall are derived using the parameters as dimensionless position of the baffles, when the baffle is single the position of baffle at $Y_{\mathrm{f}}=0.5$, when the number of baffles is two the positions of $\mathrm{Y}_{\mathrm{f}}=0.2$ and 0.5 respectively and finally when the number of baffles is three the positions of $\mathrm{Y}_{\mathrm{f}}=0.2,0.4$ and 0.6 respectively. The dimensionless length of baffle $\mathrm{L}_{\mathrm{f}}=0.2,0.3$ and 0.4 and Rayleigh number $\mathrm{Ra}$ at $10^{3}, 10^{4}$ and $10^{5}$. Prandtle number was taken as, $\operatorname{Pr}=0.74$. 
Figure (3, A-B-C) shows the effect of baffle length when the baffles are attached to active wall at $\mathrm{Y}_{\mathrm{f}}=0.5$ for one baffle , 0.2 and 0.5 for two baffles and $0.2,0.4$ and 0.6 for three baffles at Rayleigh number $\mathrm{Ra}=10^{4}$. When the length of baffle, $\mathrm{L}_{\mathrm{f}}=0.2$, the circulation of flow is very clear below the baffle near the cold wall. When the baffle length, $\mathrm{L}_{\mathrm{f}}=0.3$, the circulation of flow is started with appear above the baffle gradually while the circulation under the baffle is moved toward the hot wall. Finally, when the baffle becomes longer, $\mathrm{L}_{\mathrm{f}}=0.4$, the circulation develops above the baffle with stay the circulation below the baffle and moves more to the hot wall. Generally, the longer baffle acts like a divider in this case and modifies the flow field with respect to that cases with short baffle, the longer baffle makes circulation of flow below and above the baffle.

Generally, the temperature fields in all figures are modified and instead of isotherms of a stratified fluid, there seems to be isotherms representing a conduction dominated flow field. In the locations where the baffle is attached to the hot wall, the isotherms become almost parallel to the hot wall, resulting in a modified temperature field, which influences the entire field thereafter. The isotherms become similar to a conduction dominated temperature field. The most conduction dominated like temperature field when the position is higher and baffle length is longer.

Figure (4, A-B-C) represents the effect of Rayleigh number on steady state counter plots for the streamlines and isotherm lines for wide range of Rayleigh number at $10^{3}, 10^{4}$, and $10^{5}$ for the dimensionless baffle length, $\mathrm{L}_{\mathrm{f}}=0.2$. It can be seen from the figure that the increasing in Rayleigh number causes increasing in the temperature gradient along the vertical walls. Also, the increasing the Rayleigh number leads to increasing in the value of stream function due to the increasing in the buoyancy force.

Figure (5, A-B-C) depicts the relation ship between the Nusselt number and Rayleigh number for different dimensionless baffle length and number of baffles for the three cases. From the figures, it can be seen that the increasing in the Rayleigh number for the same length of baffle causes increasing in the Nusselt number due to more heat transfer by convection outcome from buoyancy force which increases the temperature gradient along the vertical surface and along the baffles. The increasing in the length of baffle leads to reduction in Nusselt number value because the greater heat transfer by conduction over that by convection whereas the Nusselt number equal the ratio between the heat transfer by convection to heat transfer by conduction. Also, the increasing in number of baffles leads to reduce the Nusselt number due to the drop in temperature gradient because the increasing in the dimensionless baffle length causes in the restriction of the fluid flow.

\section{Conclusions:}

In this study, a steady natural convection flow inside a trapezoidal enclosure has been studied with three cases of thin baffles attached at the heated wall while the inclined wall is cooled and the horizontal walls are well-insulated. For the different length of baffles at 0.2 , 0.3 and 0.4 , number of baffles of one, two and three and Rayleigh number at $10^{3}, 10^{4}$ and $10^{5}$, the following conclusions can be drawn as:

1-The Nusselt number increases by increasing the Rayleigh number.

2-The heat transfer increases when the Rayleigh number increased.

3-The increasing the number of baffles leads to decreases in Nusselt number.

4-The Nusselt number decreases by increasing the baffle length. 


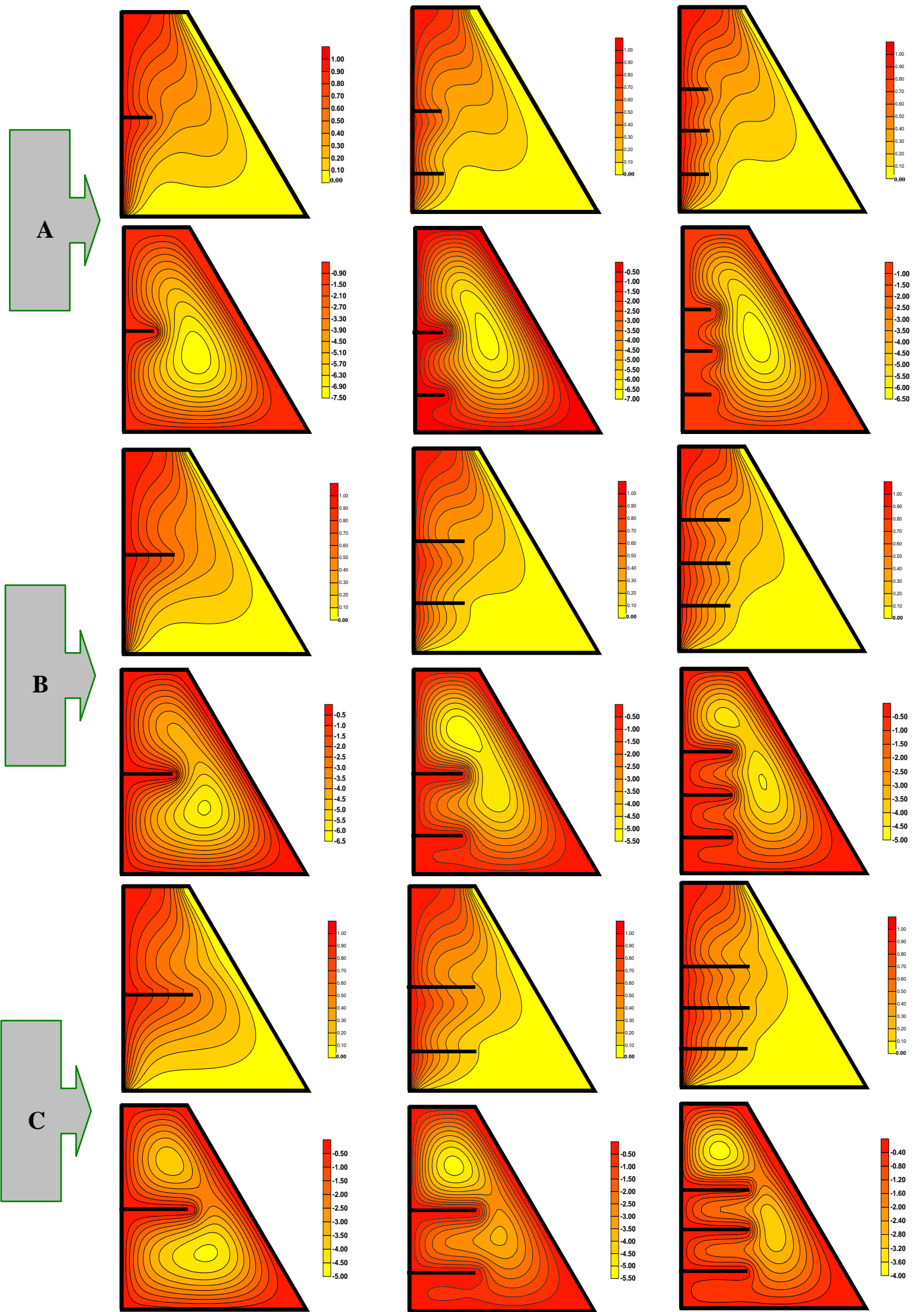

Figure (3,A-B-C ) effect of baffles length on temperature distribution and stream lines at Ravliegh number $=10^{4} . A=\left(L_{f}=0.2\right) . B=\left(L_{f}=0.3\right) . C=\left(L_{f}=0.4\right)$ 


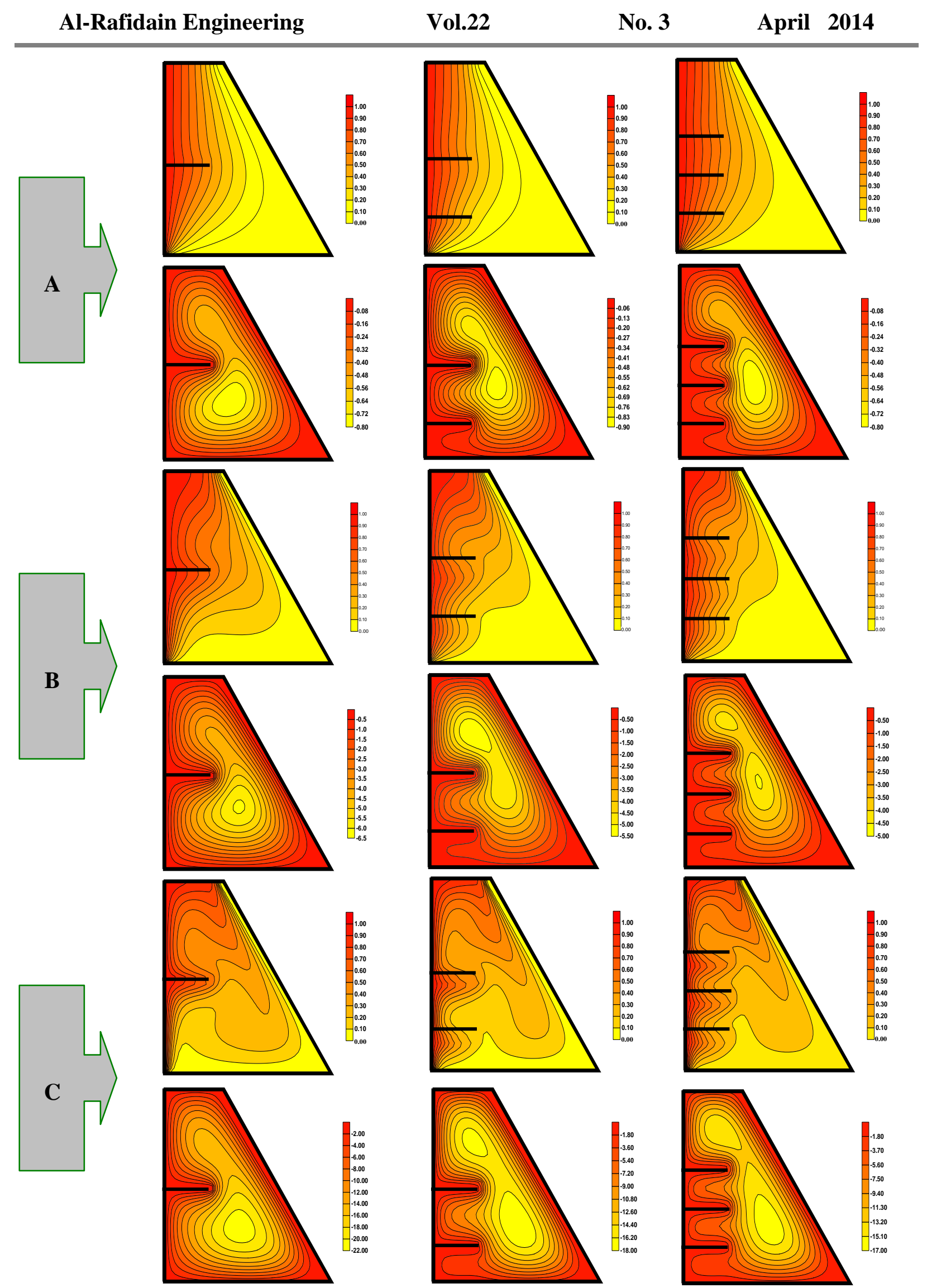

Figure (4,A-B-C ) effect of Rayliegh number on temperature distribution and stream lines at baffles length $=0.3 . \mathrm{A}=\left(\mathrm{Ra}=10^{3}\right), \mathrm{B}=\left(\mathrm{Ra}=10^{4}\right), \mathrm{C}=\left(\mathrm{Ra}=10^{5}\right)$ 

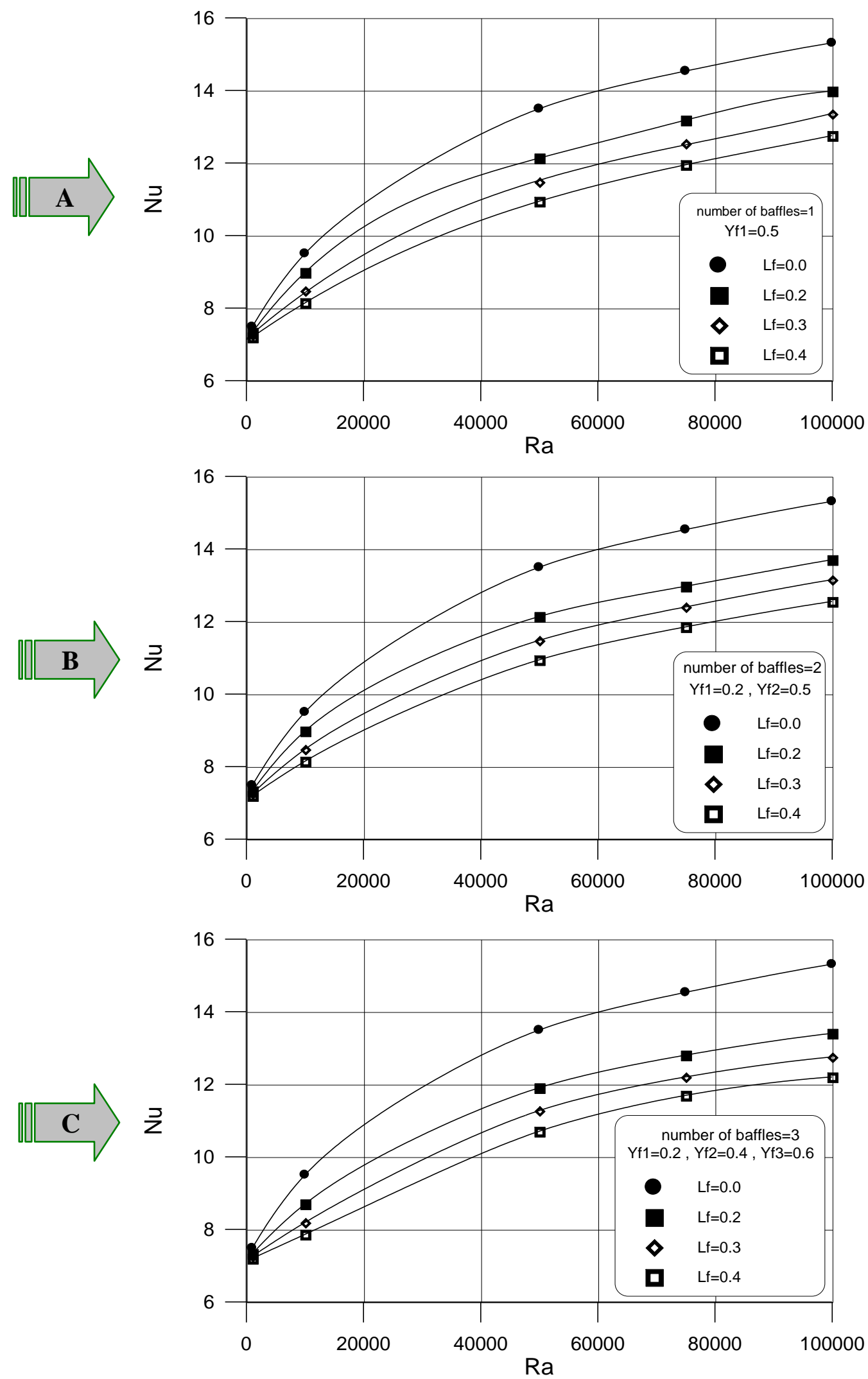

Figure (5, A-B-C ) effect of Raylieh number on Nusselt number $A=($ no. of baffle $=1), B=($ no. of baffles $=2), C=($ no. of baffles $=3)$ 


\section{References:}

[1] N. Yucel, and H. Turkoglu, "Numerical Analysis of Laminar Natural Convection in Enclosures with Fins Attached to an Active Wall", Heat and Mass Transfer 33 (1998) pp.307-314.

[2] Y.E. Karyakin, "Transient Natural Convection in Prismatic Enclosures of Arbitrary CrossSection", Int. J. Heat Mass Transfer 32 (1989) 1095-1103.

[3] M. Peric', " Natural Convection in Trapezoidal Cavities", Num. Heat Transfer AAppl. 24 (1993) 213-219.

[4] R.A. Kuyper and C.J. Hoogendoorn, "Laminar Natural Convection Flow in Trapezoidal Enclosures", Num. Heat Transfer A - Appl. 28 (1995) 55-67.

[5] H. Sadat and P. Salagnac, "Further Results for Laminar Natural-Convection in a 2Dimensional Trapezoidal Enclosure", Num. Heat Transfer A - Appl. 27 (1995) 451459.

[6] J.T. Van der Eyden, T.H. Van der Meer, K. Hanjalic, E. Biezen and J. Bruining, "DoubleDiffusive Natural Convection in Trapezoidal Enclosures", Int. J. Heat Mass Transfer 41 (1998) 1885-1898.

[7] E. Papanicolaou and V. Belessiotis, "Double-Diffusive Natural Convection in an Symmetric Trapezoidal Enclosure: Unsteady Behavior in the Laminar and the TurbulentFlow Regime", Int. J. Heat Mass Transfer 48 (2005) 191-209.

[8] Natarajan E., Tanmay B. and Roy, S.,"Natural Convection Flows in a Trapezoidal Enclosure with Uniform and Non-Uniform Heating of Bottom Wall", International Journal of Heat and Mass Transfer 51, pp. 747-756, 2008.

[9] Kasayapanand N., " A Computational Fluid Dynamic Modeling of Natural Convection in Finned Enclosure Under Electric Field", Applied Thermal Engineering 29, pp.131141,2009 .

[10] Tanmay B. Roy S. Amit S., Bishun D. and Pandey C.,"Natural Convection Flow Simulation for Various Angles in a Trapezoidal Enclosure with Linearly Heated Side Wall(s)", International Journal of Heat and Mass Transfer 52, pp. 4413-4425, 2009.

[11] Tanmay B., Ramakrishna D., Royb S. Anjanna M, and Pop. I., "A Comprehensive Heatline Based Approach for Natural Convection Flows in Trapezoidal Enclosures: Effect of Various Walls Heating", International Journal of Thermal Sciences 50, pp. 1385-1404, 2011.

[12] Moukalled, F. and Darwish, M."Natural Convection in a Trapezoidal Enclosure Heated From The Side with a Baffle Mounted on its Upper Inclined Surface", Department of Mechanical Engineering, American University of Beirut.

The work was carried out at the college of Engineering. University of Mosul 